\title{
Power Grid Fault Diagnosis Method Using Intuitionistic Fuzzy Petri Nets Based on Time Series Matching
}

\author{
Mingyue Tan $(\mathbb{D}$, Jiming Li $(\mathbb{D}$, Xiangqian Chen $(\mathbb{D})$, and Xuezhen Cheng $(\mathbb{D})$ \\ Department of the Electrical Engineering \& Automation, Shandong University of Science and Technology, \\ 579 Qianwangang Road, Huangdao District, Qingdao, Shandong Province 266590, China
}

Correspondence should be addressed to Xuezhen Cheng; zhenxc6411@163.com

Mingyue Tan and Jiming Li contributed equally to this work.

Received 25 March 2019; Revised 10 May 2019; Accepted 10 June 2019; Published 21 July 2019

Guest Editor: Chun Wei

Copyright (C) 2019 Mingyue Tan et al. This is an open access article distributed under the Creative Commons Attribution License, which permits unrestricted use, distribution, and reproduction in any medium, provided the original work is properly cited.

To improve the reliability of power grid fault diagnosis by enhancing the processing ability of uncertain information and adequately utilizing the alarm information about power grids, a fault diagnosis method using intuitionistic fuzzy Petri Nets based on time series matching is proposed in this paper. First, the alarm hypothesis sequence and the real alarm sequence are constructed using the alarm information and the general grid protection configuration model, and the similarity of the two sequences is used to calculate the timing confidence. Then, an intuitionistic fuzzy Petri Nets fault diagnosis model, with an excellent ability to process uncertain information from intuitionistic fuzzy sets, is constructed, and the initial place value of the model is corrected by the timing confidence. Finally, an application of the fault diagnosis model for the actual grid is established to analyze and verify the diagnostic results of the new method. The results for some test cases show that the new method can improve the accuracy and fault tolerance of fault diagnosis, and, furthermore, the abnormal state of the component can be inferred.

\section{Introduction}

With the development of the power grid, an increasing number of new energy sources, such as solar energy, photovoltaics, and wind energy [1], have been integrated into power grids, which poses a potential threat to the safe operation of the grids [2]. It is becoming more and more urgent to form a fast and accurate power grid fault diagnosis method. At present, the mainly grid fault diagnosis method is that power grid dispatchers use the data which from Supervisory Control And Data Acquisition (SCADA) and their own experience to analyze the fault. However, the accuracy and speed of traditional fault diagnosis methods are difficult to meet the requirements of current power grids when complex faults [3] occur, so many automatic diagnosis methods are proposed as follows: Expert Systems [4], Artificial Neural Networks $[5,6]$, Bayesian Networks [7, 8], Rough Sets [9], and Petri Nets $[10,11]$. In recent years, due to fuzzy Petri Nets' advantages of rapid concurrency and the ability to process uncertain information, the research adapting fuzzy Petri Nets to grid fault diagnosis has attracted increasing attention.

Wang L, Sun J [12, 13] proposed a fault diagnosis model based on fuzzy Petri Nets to solve the uncertainty of protection and circuit breaker action in grids. The matrix dimension reduction method has improved the calculation speed. Wang Y N and Cheng X Z $[14,15]$ used weighted fuzzy Petri Nets and the hierarchical transition method to analyze grid faults. In order to stratify the transition set and optimize the algorithm, the two-layer general model was established for each component. In [16], a fuzzy Petri Nets fault diagnosis method, considering protection and circuit breaker action timing, was proposed, which improved the ability of handling uncertain information and fault tolerance. Cheng X Z [17] proposed a fuzzy Petri Nets diagnosis method based on directional weighting. In this model, subnet models were established for each propagation direction, and different weights were assigned according to the degree of the influence of different components on the results. In [18], a weighted fuzzy Petri Nets 
fault diagnosis method, based on multisource information fusion, was proposed, which introduced electrical quantity and took the time series attribute into consideration. In addition, fuzzy neural Petri Nets [19] were used in the field of fault diagnosis.

The fuzzy Petri Nets fault diagnosis models, mentioned above, take into account the uncertainty of protection and circuit breaker trip information, as well as the calculation and fault tolerance of the model. However, the impact of uncertain and incomplete information [21] on the fault diagnosis results is not fully considered in these models. In particular, timing data in the alarm information also needs to be further mined, and the use of big data to solve complex problems [22] in fault diagnosis has become a trend too.

Petri Nets are directed graph structures with timing constraints, and the temporal logic of the alert information is automatically considered when generating the Petri Nets model in an online application. However, the received alert information may have various conditions, such as rejection, misoperation, and timing disorder, which may reduce the accuracy of the diagnosis results. Against the background of the above research, the intuitionistic fuzzy Petri Nets fault diagnosis model, based on time series matching, is established to process time series information. The timing information is further mined using the method of timing matching, and the sequence difference and time difference at the time of the fault are calculated by the Edit Distance and the Dynamic Time Warping (DTW) Distance, respectively. At the same time, the description of information uncertainty is more precise by the intuitionistic fuzzy set considering the degree of membership and nonaffiliation of the information. This paper mainly does the following work.

(1) To study the timing properties of alert information, the time series confidence is calculated by analyzing the timing constraint relationship between the protection and the circuit breaker to verify and filter the alarm information and correct the confidence value of the initial position.

(2) To establish an intuitionistic fuzzy Petri Nets fault diagnosis model, the intuitionistic fuzzy algorithm is used to deal with the membership degree and nonmembership degree relationship of the alarm information, when the fault occurs, which can improve the model's ability to deal with uncertain and incomplete alarm information.

(3) To establish a two-layer fault diagnosis model, after the fault occurs, the nonmembership value of the terminal position is modified according to the number of remote backup protection actions of the component, and the membership value is optimized by the hierarchical transition technique and the Gaussian function.

The reasoning process based on matrix operation is given.

\section{Intuitionistic Fuzzy Time Petri Nets}

2.1. The Basic Theory of Intuitionistic Fuzzy Sets. The intuitionistic fuzzy set [25] has three aspects: membership degree, nonmembership degree, and hesitation degree. Therefore, the set is more accurate concerning the description of uncertain and incomplete information. Intuitionistic fuzzy sets can be defined according to the following [26].
Definition 1. Assuming that $X$ is a given theoretical domain, the definition of the intuitionistic fuzzy sets of domain $X$ is as follows:

$$
A=\left\{\left\langle x, \mu_{A}(x), \gamma_{A}(x)\right\rangle \mid x \in X\right\}
$$

(1) $0 \leq \mu_{A}(x)+\gamma_{A}(x) \leq 1$, where $\mu_{A}(x): x \rightarrow[0,1]$ and $\gamma_{A}(x): x \longrightarrow[0,1]$ represent the membership function and the nonmembership function of set $\mathrm{A}$, respectively, and for any element in set $A, x \in X, 0 \leq \mu_{A}(x)+\gamma_{A}(x) \leq 1$.

(2) The function pair $\left(\mu_{A(x)}, \gamma_{A(x)}\right)$ is defined as the intuitionistic fuzzy index in the $X$ domain, which is composed of membership degree $\mu_{A(x)}$ and nonmembership degree $\gamma_{A(x)}$.

(3) $\pi_{A}(x)=1-\mu_{A}(x)-\gamma_{A}(x)$ is set as the degree of hesitation of $x$ in the intuitionistic fuzzy set $A$ in the domain of $X$, indicating that $x$ belongs to the degree of uncertainty of set $A$. Additionally, for any $x \in X, 0 \leq \pi_{A}(x) \leq 1$.

2.2. Time Series Model in the Power Grid. The time series model in the grid is defined on the basis of study [20].

$x=(v, t)$ is set as a single element in the timing collection, and the alert information $v$ is defined as a triple: $v=(A, \Delta t, S)$

(1) $A$ indicates component action or alarm information.

(2) $\Delta t$ represents the length of the error of time, $\Delta t$ and $t$ constitute a time constraint, and the time when event $A$ occurs is $[t-\Delta t / 2, t+\Delta t / 2]$.

(3) $S$ denotes a fuzzy flag, $S=0: x=(v, t)$ denotes a fuzzy term, and $S=1: x=(v, t)$ denotes a certain term. The introduction of fuzzy items has a good distinction between uncertain and incomplete information caused by misoperation, refusal, and information loss in the power grid, which is beneficial for improving the accuracy of diagnosis. When $A_{i}$ is indicated as an electrical equipment failure (Busbar, Line, Transformer) or circuit breaker and circuit breaker failure protection simultaneously trip, the time element $x_{i}=\left(v_{i}, t_{i}\right)$ is a fuzzy item.

2.3. Time Series Reasoning Process. The application of time series information in grid fault diagnosis, in [15, 17], is only used to filter alarm information. In this paper, time series similarity matching is used to calculate the Edit Distance and DTW Distance between the actual alarm time series and the alarm hypothesis time series, which is then converted to time confidence that can be used to correct the probability of the model.

The Edit Distance is a measure used to calculate the distance between two strings of sequences, which can be expressed as the minimum number of edit operations required to convert a string into another string (editing operations include insert, delete, and replace).

For example, string sequences $X=\left\{x_{1}, x_{2}, \ldots, x_{n}\right\}, \mathrm{Y}=$ $\left\{y_{1}, y_{2}, \ldots, y_{n}\right\}$, the Edit Distance $D_{n, k}$ can be calculated from $D_{0,0}$ by

$$
\begin{aligned}
& D_{i, j} \\
& =\left\{\begin{array}{l}
0 \\
\min \left(D_{i-1, j-1}+L\left(x_{i}, y_{i}\right), D_{i-1, j}+1, D_{i, j-1}+1\right) \\
i>0 \text { or } j>0
\end{array} \quad i=j=0\right.
\end{aligned}
$$


In the formula, if $x_{i}=y_{i}$, then $L\left(x_{i}, y_{i}\right)=0$; otherwise, $L\left(x_{i}, y_{i}\right)=1$.

Editing Distance has been already a mature calculation method. However, due to the high uncertainty of information in the grid fault (the loss of, and erroneous, information, as well as timing chaos), it is difficult to make accurate judgments on sequences that are not synchronized. In this paper, the Editing Distance is combined with the Dynamic Time Warping Distance to form a time similarity matching calculation method to increase the processing ability of the asynchronous information. The specific discussion is as follows.

For time series $X$ and time series $Y$,

$$
\begin{aligned}
X & =\left\{x_{1}=\left(V x_{1}, t_{x 1}\right), x_{2}=\left(V x_{2}, t_{x 2}\right), \ldots, x_{n}\right. \\
& \left.=\left(V x_{n}, t_{x n}\right)\right\} \\
Y & =\left\{y_{1}=\left(V_{y 1}, t_{y 1}\right), y_{2}=\left(V_{y 2}, t_{y 2}\right), \ldots, y_{n}\right. \\
& \left.=\left(V_{y m}, t_{y m}\right)\right\}
\end{aligned}
$$

$(n \leq m)$

If $X$ and $Y$ are not obscured, the distance [20] between them can be defined as

$$
\begin{aligned}
& D(X, Y)=a D_{\text {edit }}\left(X, Y_{s}\right)+b D_{\text {time }}\left(X, Y_{s}\right) \\
& D_{\text {time }}\left(X, Y_{s}\right)=\sum_{x_{i}\left|\in X, x_{i}\right| \notin Y_{s}} 1 \\
& D_{\text {time }}\left(X, Y_{s}\right) \\
& =\sum_{x_{i} \mid=y_{j}^{\prime}, \beta \geq \gamma}\left(\frac{4}{\pi} \arctan \left(\frac{2\left|t_{x i}-t_{y j}{ }^{\prime}\right|}{\Delta t_{x i}+\Delta t_{y j}^{\prime}}\right)-1\right)
\end{aligned}
$$

(1) $\beta=\left|t_{x i}-t_{y j}{ }^{\prime}\right|, \gamma=\left|\left(\Delta t_{x i}+\Delta t_{y j}{ }^{\prime}\right) / 2\right| i=1,2, \ldots, n ; j=$ $1,2, \ldots, p$.

(2) $Y_{s}=\left(y_{1}^{\prime}, y_{1}^{\prime}, \ldots y_{p}{ }^{\prime}\right)$. For any $y_{i}^{\prime} \mid \in Y_{s}$, there is $y_{i}^{\prime} \mid \epsilon$ $X$, and $y_{i}^{\prime}$ is the element of time series $Y,(i=1,2, \ldots, p)$, and $D_{\text {edit }}\left(X, Y_{s}\right)$ denotes the Edit Distance of the time series $X$ and $Y_{s}$ for identifying information loss and timing disorder. Since $Y_{s}$ is a time subsequence of the $Y$ set, the simplified formula applies to the general case.

(3) $D_{\text {time }}\left(X, Y_{s}\right)$ represents the DTW Distance between time series $X$ and $Y_{s} ; a$ is the weight of the Edit Distance, and $b$ is the weight of the DTW Distance. Due to the special information, such as information error, information loss, or timing disorder, the alarm information, received by the system, may cause large deviations in timing matching. Based on this, the weight coefficients $a$ and $b$ are defined to quantify the deviation in order to adjust the proportion of the Edit Distance and the DTW Distance. The smaller the difference between the two time series, the more similar they are.

The confidence calculation method for timing matching is defined in [20], and the calculated distance between the actual alarm time series and the alarm hypothesis time series is mapped to the $(0,1)$ interval by $(7)$. The smaller the distance between the two time series, the higher the confidence level obtained.

$$
C_{X}= \begin{cases}1 & \mathrm{D}(\mathrm{X}, \mathrm{Y}) \leq 1 \\ \frac{1}{\mathrm{D}(X, Y)} & 1<\mathrm{D}(\mathrm{X}, \mathrm{Y}) \leq 10 \\ 0.1 & \mathrm{D}(\mathrm{X}, \mathrm{Y})>10\end{cases}
$$

2.4. Intuitionistic Fuzzy Time Petri Nets (IFTPN). Intuitionistic Fuzzy Time Petri Nets (IFTPN) can be defined as a seventuple, IFTPN $=\left\{P, T_{\lambda}, F, T_{t}, I, O, M_{0}\right\}$.

(1) $P=\left\{p_{1}, p_{2}, p_{3}, \ldots, p_{n}\right\}$ indicates a collection of finite places in IFIAPN.

(2) $T_{\lambda}=\left\{\lambda_{1}, \lambda_{2}, \lambda_{3}, \ldots, \lambda_{n}\right\}$ indicates a set of finite transitions in IFIAPN.

(3) $F=\left\{f_{1}, f_{2}, f_{3}, \ldots, f_{\mathrm{n}}\right\}$ indicates a set of transition thresholds in IFIAPN, where $f_{j}=\left(\alpha_{j}, \beta_{j}\right), j=1,2,3, \ldots, m$ are intuitionistic fuzzy sets, and $\alpha_{j} \geq 0, \beta_{j} \geq 0$ represent the uncertainty and the uncertainty of transition $\lambda_{j}$, respectively.

(4) $T_{t}=\left\{t_{1}, t_{2}, t_{3}, \ldots, t_{n}\right\}$ indicates the time status information of the initial places.

(5) $I$ represents the input matrix $I=\left(W_{I i j}\right)_{n \times m}, W_{I i j}$ represents the logic element, $W_{I i j} \in[0,1]$, and $\sum_{0 \leq i \leq n} W_{I i j}=$ 1 . If there is a directed arc, from place $p_{i}$ to transition $t_{i}$, then the value of $W_{I i j}$ is the weight of the directed arc. If there is no directed arc from $p_{i}$ to $t_{i}$, then $W_{I i j}=0, i=1,2,3, \ldots, n ; j=$ $1,2,3, \ldots, m$

(6) $O$ indicates the output matrix, $O=\left(W_{O i j}\right)_{n \times m}, W_{O i j}$ represents the logic element, and $W_{\text {Oij }} \in[0,1]$. If there is a directed arc from transition $t_{j}$ to place $p_{i}$, then the value of $W_{\text {Oij }}$ is $c_{j}$ of the confidence of the rule $t_{j}$, and $c_{j}=\left(\mu_{c}, \gamma_{c}\right)$ represents the weight parameter of the directed arc from transition $t_{j}$ to place $p_{i}$. If there is no directed arc from $t_{j}$ to $p_{i}$, then $W_{\text {Oij }}=0, i=1,2,3, \ldots, n ; j=1,2,3, \ldots, m$.

(7) $M_{0}$ is the initial state, $M_{0}=$ $\left[m_{0}\left(p_{1}\right), m_{0}\left(p_{2}\right), m_{0}\left(p_{3}\right), \ldots, m_{0}\left(p_{i}\right)\right], m_{0}\left(p_{i}\right)$ is the initial state of the proposition $p_{i}, M_{0}\left(p_{i}\right)=\left(\mu_{i}, \gamma_{i}\right)$, where $\mu_{i}$ represents the degree of certainty of the place $p_{i}, \gamma_{i}$ represents the uncertainty of the place $p_{i}$, and $M_{0}\left(p_{i}\right) \in[0,1]$.

\section{Grid Fault Diagnosis Based on Time Series Intuitionistic Fuzzy Petri Nets}

In this paper, the IFTPN grid fault diagnosis model is constructed by the time series similarity matching method, including the intuitionistic fuzzy Petri Nets theory and the time series characteristics of grid component faults. The model focuses on the timing properties of protection\circuit breaker action, in grid faults, and adopts a layered transition model structure, which can be used to visually describe the logical relationship and timing characteristics of protection and circuit breakers.

3.1. IFTPN-Based Modeling Method. According to the relay protection setting rules, the components in the power grid are equipped with corresponding primary protection and backup protection, and different protections are provided for 
different components. For example, the protection of the Busbar is composed of primary protection and remote backup protection. The protection of the line and the transformer provides corresponding primary protection, near backup protection, and far backup protection at the sending end and the receiving end.

The IFTPN model is built according to the above rules. When the grid fails, the protection and circuit breakers act in a sequence (main protection, main protection corresponding to the circuit breaker, near backup protection, near backup protection corresponding to the circuit breaker, far backup protection, and remote backup protection corresponding to the circuit breaker) to stop the action until the problem is resolved.

The time stamp of the first piece of alarm information received is used as a reference point. The alarm hypothesis time series is generated according to the component action delay: main protection $(10 \mathrm{~ms}, 20 \mathrm{~ms})$, near backup protection (485 ms, $545 \mathrm{~ms})$, far backup protection $(960 \mathrm{~ms}, 1070 \mathrm{~ms})$, and circuit breaker trip delay ( $20 \mathrm{~ms}, 40 \mathrm{~ms})$.

The IFTPN fault diagnosis model for Busbars, transformers, and lines is established, according to the actual grid model, shown in Figure 1. As shown in Appendix A, Figures 5 and 6 are fault diagnosis models for single Busbar $A_{1}$ and double Busbar $\mathrm{B}_{2}$, respectively, and Figure 7 is the model for line $\mathrm{L}_{2}$. The model structures of the transformer and line are the same; only the protection and circuit breaker components are different. This information is not included here.

To facilitate the description of the algorithm and simplify the reasoning process, the operator is defined as follows:

Suppose $A, B$, and $C$ make up the $m \times n$ order matrix, $D$ is the $m \times q$ matrix, and $E$ is the $q \times n$ matrix.

(1) Direct multiplication operator $\bullet: C=D \bullet E$, that is, $c_{i j}=a_{i j} b_{i j}$.

(2) Comparison operator $\Theta: C=A \Theta B$; that is, $c_{i j}=(1,0)$ when $a_{i j} \geq b_{i j}$; otherwise, $c_{i j}=(0,1)$.

(3) Multiplication operator $\otimes: C=D \otimes E$; then $c_{i j}=$ $\max _{1 \leq k \leq q}\left(d_{i k} e_{k j}\right)$.

(4) Addition operator $\oplus: C=A \oplus B$; then $c_{i j}=$ $\max \left(a_{i j}, b_{i j}\right)$.

The components in the grid of this paper adopt the modeling method of hierarchical transition. For the Busbar, the first layer of the model is a submodel of the sending end and receiving end, including two layers of transitions, and the integrated model has one layer of transitions in the second layer. For the line, the first layer of the model includes two transitions in each direction, and the second layer of the model has one transition. When the topology changes, the architecture and operation matrix of the improved model are less adjusted, and the model is more versatile, because it does not need to make any modifications to the model but only update the values of the initial library in the first layer model.

3.2. Algorithm Improvement. The reasoning process of the algorithm described in [13] is complicated, and the number of iteration calculations is too many. Compared with study [13], the algorithm in [11] is optimized, but it is not applied in the process of matrix reasoning. The algorithm is improved in the following ways in this article.

\section{(1) Algorithm Optimization for Certainty}

$$
\psi_{\mu}^{k}=f_{\psi}\left(O_{n \times 1}^{k} \otimes \psi_{\mu m \times 1}^{k-1}\right)
$$

The deterministic value of the interlayer confidence is processed by the Gaussian function, which is applied to the matrix deduction process. $f_{\psi}(x)$ is the Gaussian function [13]:

$$
f_{\psi}(x)=e^{-3(x-1)^{2}}
$$

The application of this function can make the calculation results more in line with the characteristics of the fault diagnosis and make the probability of failure more of an ideal value within $(0,1)$. Assuming that Figure 2 is the Busbar $\mathrm{B} 1$ sending end model, place $\mathrm{P}_{1}$ represents the line main protection, and place $\mathrm{P}_{2}$ is the protection corresponding to the circuit breaker, if the uploaded protection and circuit breaker action information satisfy the time constraint, the deterministic value of place $\mathrm{P}_{1}$ is set to 0.8564 , and the deterministic value of place $P_{2}$ is set to 0.8333 . The accumulative determinant value of transition input is $0.8564 \times 0.5+0.8333 \times 0.5=0.8448$. After processing using the Gaussian function, the certainty value of place $\mathrm{P}_{5}$ is $f_{\psi}(0.8448)=0.93028$, which is significantly higher than the certain degree, before processing. This paper specifies that the transition is triggered by the deterministic value. The corresponding calculation is performed for each transition trigger, until the final vector of the model is obtained.

\section{(2) Algorithm Optimization of Uncertainty}

For a faulty component in the system, when the primary protection of the component and the corresponding circuit breaker are rejected, the backup protection of the component will act. The higher the number of protection and circuit breaker actions in the fault propagation direction, the greater the fault probability of the component, and the lower the uncertainty of the corresponding component actions. According to the above situation, the uncertainty value of the terminal place in the direction of the fault propagation is corrected by formula (11) in this paper.

$$
\psi_{\gamma}^{k}=\gamma_{\psi}^{\prime}\left(O_{n \times 1}^{k} \otimes \psi_{\gamma_{m \times 1}}^{k-1}\right)
$$

The uncertainty of the terminal place in the component failure propagation direction is set to $\gamma$, according to the actual spreading direction of the faulty component, after time series processing. The value of the uncertainty, after correction, is

$$
\gamma^{\prime}=\frac{\gamma}{N u m}
$$

The algorithm for the entire confidence is described as

$$
\psi_{m \times 1}^{k}=\left(\psi_{\mu}^{k}, \psi_{\gamma}^{k}\right)
$$

The improved algorithm includes the cumulative calculation of transition input values, threshold comparisons, and vector calculations for the terminal place. The specific confidence reasoning process is as follows. 
(1) The initial state is set to $M_{n \times 1}^{0}$. The input intuitionistic fuzzy value of the transition is calculated.

$$
\eta_{m \times 1}^{k}=I_{n \times m}^{T} \cdot M_{n \times 1}^{k}
$$

(2) The threshold of the transition is compared with the input intuitionistic fuzzy value of the transition, and then the transition set $\varphi_{m \times 1}^{k}$, capable of triggering the transition, is obtained.

$$
\varphi_{m \times 1}^{k}=\eta_{m \times 1}^{k} \Theta F_{m \times 1}
$$

(3) The input intuitionistic fuzzy value $\psi_{m \times 1}^{k}$, which can trigger the transition based on the obtained set $\varphi_{m \times 1}^{k}$ of the transitions that can be excited, is calculated.

$$
\psi_{m \times 1}^{k}=\eta_{m \times 1}^{k} \bullet \varphi_{m \times 1}^{k}
$$

(4) The discriminant value $M_{n \times 1}^{k+1}$ of the place, obtained by $k+1$ calculations, is calculated.

$$
M_{n \times 1}^{k+1}=O_{n \times 1}^{k} \otimes \psi_{m \times 1}^{k} \oplus M_{n \times 1}^{k}
$$

(5) If $M_{n \times 1}^{k+1}=M_{n \times 1}^{k}$, then the confidence matrix of the Petri Nets is stable; that is, the reasoning ends; otherwise, let $k=k+1$ and return to step (4).

\subsection{Settings of Simulation Parameters}

3.3.1. Identification Value Data. This paper uses the statistical probability data of long-term actual operation, provided by study [24]. The data are weighted by the timing confidence to assign values to the protection place and the circuit breaker place. The following settings are provided for the refusal, misoperation, and unoperated component place of the protection and circuit breakers in the grid.

Definition $\left(\mu_{1}, \gamma_{1}\right)$ is the identification value when the alarm information exists, and $\left(\mu_{2}, \gamma_{2}\right)$ is the identification value when the alarm information does not exist, or the protection and the circuit breaker are rejected or misplaced. The relationship is as follows:

$$
\begin{aligned}
& \mu_{2}=\omega \times \mu_{1} \\
& \gamma_{2}=\frac{\gamma_{1}}{\omega}
\end{aligned}
$$

The parameter $\omega$ is used to express great uncertainty in action fault events.

3.3.2. Setting the Model Network Parameters. (1) The initial value of the initial component place and virtual place is $(0,1)$.

(2) The input arc weight is $\omega=(1 / N)$, where $N$ is the number of inputs, from place to transition. If the place, connected through the output arc, is the component place, the output arc has an identification value of $(0.95,0.025)$; if the place, connected by the output arc, is a virtual place, the output arc has an identification value of $(1,0)$.

(3) Learning from study [24], it must be ensured that the model's fault-tolerant transition threshold is set to a value $(0.2,0.7)$.

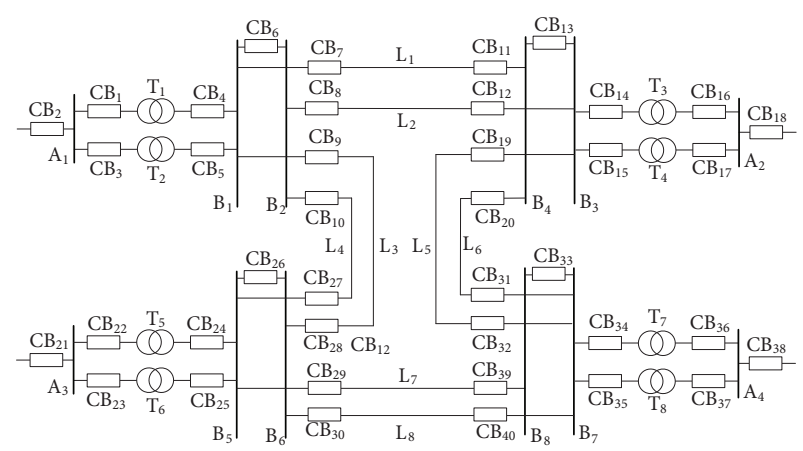

FIgURE 1: Actual grid model.

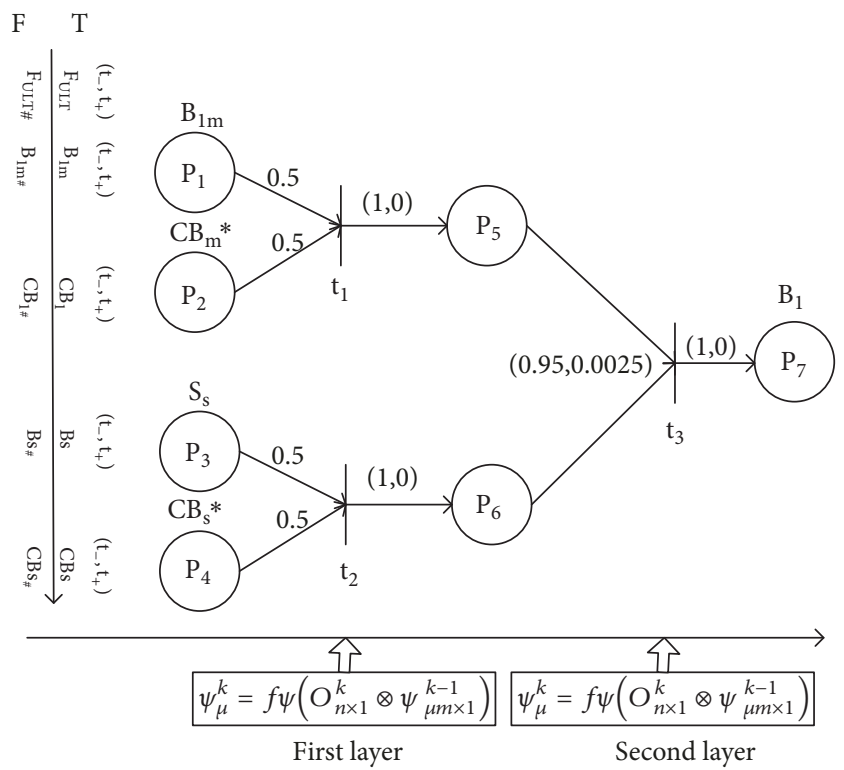

FIGURE 2: Basic structure diagram of IFTPN.

3.3.3. Fault Degree Parameter Threshold Setting. The metric function of the probability of failure of the device is

$$
f(N)= \begin{cases}\frac{\mu-\gamma}{\mu}, & \mu>\gamma \\ 0, & \mu<\gamma\end{cases}
$$

where $N$ represents the faulty component and $(\mu, \gamma)$ represents the intuitionistic fuzzy identification value of the faulty component. When the metric value $f(N)>\theta$ of the faulty element, it is determined that the component $N$ is faulty, where $\theta$ is the threshold for determining whether the component $N$ has a fault. To ensure accurate operation, the degree of uncertainty of the fault should be much greater than the uncertainty, so the value of $\theta$ is set to 0.56 .

\section{IFTPN Troubleshooting Process}

According to the fault alarm information, received by the power dispatching center, the fault area of the system is searched, the suspected fault component set is obtained, and 


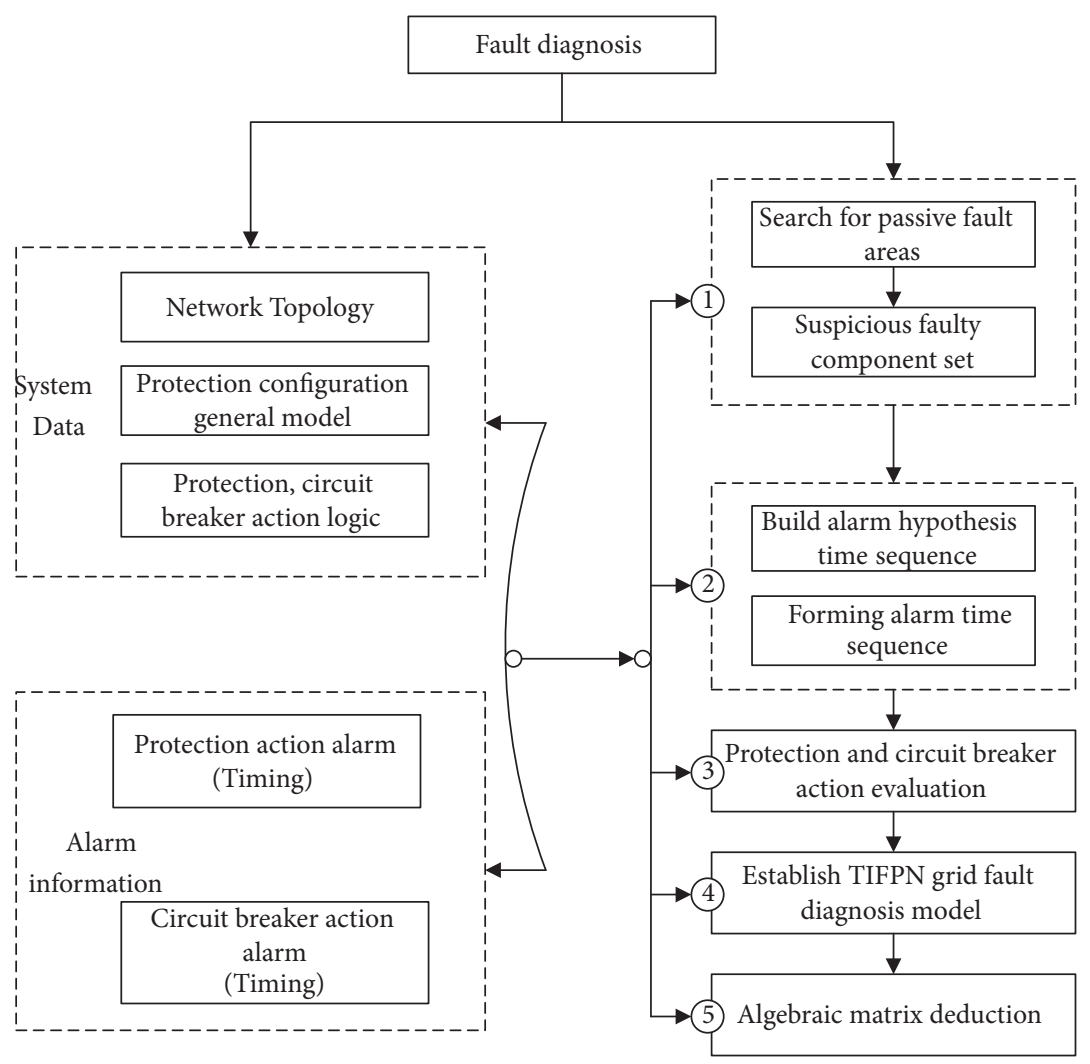

Figure 3: Fault diagnosis model frame structure.

TABLE 1: Comparison of the fault degree of the two methods in study [20].

\begin{tabular}{lccr}
\hline Component & Transmission line $\mathrm{L}_{8}$ & Busbar $\mathrm{B}_{7}$ & Transmission line $\mathrm{L}_{6}$ \\
\hline Weighted fuzzy Petri nets & 0.76745 & 0.82152 & 0.51649 \\
\hline Time-series weighted fuzzy Petri nets & 0.76745 & 0.79695 & 0.2 \\
\hline This article & 0.96723 & 0.9975 & 0.1 \\
\hline
\end{tabular}

TABLE 2: Comparison of the diagnostic results under the same conditions.

\begin{tabular}{|c|c|c|c|c|c|c|}
\hline \multirow{2}{*}{ Number } & \multirow{2}{*}{ Alarm information } & \multirow{2}{*}{$\begin{array}{l}\text { Suspected } \\
\text { Faulty device }\end{array}$} & \multicolumn{4}{|c|}{ Fault probability } \\
\hline & & & $\begin{array}{l}\text { The } \\
\text { method of } \\
\text { [13] }\end{array}$ & $\begin{array}{l}\text { The } \\
\text { method of } \\
\text { [23] }\end{array}$ & $\begin{array}{l}\text { The } \\
\text { method of } \\
{[24]}\end{array}$ & $\begin{array}{l}\text { The } \\
\text { method of } \\
\text { this paper }\end{array}$ \\
\hline 1 & $\begin{array}{c}\mathrm{L}_{0407 \mathrm{Rm}} ; \mathrm{L}_{0407 \mathrm{Sm}} ; \\
\mathrm{CB}_{0407} ; \mathrm{CB}_{0704} \text { act }\end{array}$ & $\mathrm{L}_{0407}$ & 0.99 & 0.8910 & 0.9968 & 0.9673 \\
\hline 2 & $\begin{array}{c}\mathrm{L}_{0407 \mathrm{Rm}} ; \mathrm{L}_{0407 \mathrm{Sm}} ; \\
\mathrm{L}_{0807 \mathrm{Rs}} ; \mathrm{L}_{0907 \mathrm{Rs}} ; \mathrm{CB}_{0407} \\
\mathrm{CB}_{0807} ; \mathrm{CB}_{0907} \text { act }\end{array}$ & $\mathrm{L}_{0407}$ & 0.8798 & 0.8178 & 0.9601 & 0.9640 \\
\hline 3 & $\begin{array}{c}\mathrm{L}_{0407 \mathrm{Rm}} ; \mathrm{L}_{0407 \mathrm{Sm}} \\
\mathrm{CB}_{0704} \text { act }\end{array}$ & $\mathrm{L}_{0407}$ & 0.5705 & 0.7143 & 0.9506 & 0.9553 \\
\hline 4 & $\begin{array}{l}\mathrm{L}_{0407 \mathrm{Rm}} ; \mathrm{CB}_{0407} ; \\
\mathrm{CB}_{0704} ; \text { act }\end{array}$ & $\mathrm{L}_{0407}$ & $0 . .6016$ & 0.7125 & 0.9503 & 0.9550 \\
\hline 5 & $\begin{array}{c}\mathrm{L}_{0407 \mathrm{Rm}} ; \mathrm{L}_{0407 \mathrm{Sm}} \\
\mathrm{L}_{0807 \mathrm{Rs}} ; \mathrm{L}_{0907 \mathrm{Rs}} ; \mathrm{CB}_{0807} \\
\mathrm{CB}_{0907} \text { act }\end{array}$ & $\mathrm{L}_{0407}$ & 0.5012 & 0.6411 & 0.9385 & 0.9412 \\
\hline 6 & $\mathrm{~L}_{0407 \mathrm{Sm}}$ act & $\mathrm{L}_{0407}$ & 0.4286 & 0.2688 & 0.1341 & 0 \\
\hline
\end{tabular}


TABLE 3: Comparison of the proposed method and three existing methods for grid fault diagnosis.

\begin{tabular}{|c|c|c|c|c|}
\hline Method & $\begin{array}{l}\text { Processing of timing } \\
\text { information }\end{array}$ & $\begin{array}{c}\text { Consider } \\
\text { uncertainty }\end{array}$ & Modeling form & Performance \\
\hline Study [20] & $\begin{array}{l}\text { Using time series } \\
\text { matching method, } \\
\text { making full use of } \\
\text { time-scale } \\
\text { information }\end{array}$ & No & $\begin{array}{l}\text { Timing matching } \\
\text { model }\end{array}$ & $\begin{array}{l}\text { The calculation speed is fast } \\
\text { but only considers the } \\
\text { timing factor; too singular }\end{array}$ \\
\hline Study [15] & $\begin{array}{l}\text { Timing not } \\
\text { considered }\end{array}$ & No & $\begin{array}{l}\text { Fuzzy Petri nets } \\
\text { model }\end{array}$ & $\begin{array}{l}\text { High diagnostic efficiency; } \\
\text { good fault tolerance; did } \\
\text { not consider the impact of } \\
\text { timing }\end{array}$ \\
\hline Study [24] & $\begin{array}{l}\text { Timing not } \\
\text { considered }\end{array}$ & Yes & $\begin{array}{l}\text { Intuitionistic Fuzzy } \\
\text { Petri Nets Model }\end{array}$ & $\begin{array}{l}\text { Full consideration of the } \\
\text { impact of uncertain, } \\
\text { incomplete information but } \\
\text { does not take timing into } \\
\text { account }\end{array}$ \\
\hline $\begin{array}{l}\text { The } \\
\text { method of } \\
\text { this paper }\end{array}$ & $\begin{array}{l}\text { Using the time series } \\
\text { matching method, } \\
\text { making full use of } \\
\text { time-scale } \\
\text { information }\end{array}$ & Yes & $\begin{array}{c}\text { Intuitionistic Fuzzy } \\
\text { Petri Nets Model } \\
\text { Based on Time Series } \\
\text { Matching }\end{array}$ & $\begin{array}{l}\text { Fully consider the timing } \\
\text { information, and uncertain } \\
\text { and incomplete } \\
\text { information; better fault } \\
\text { tolerance; precise fault } \\
\text { diagnosis }\end{array}$ \\
\hline
\end{tabular}

TABLE 4: The code of alarm information.

\begin{tabular}{lc}
\hline Number & Fault type \\
\hline $\mathrm{a}_{1}$ & $\mathrm{~L}_{2}$ sending end main protection action \\
\hline $\mathrm{a}_{2}$ & $\mathrm{~L}_{2}$ receiving end main protection action \\
\hline $\mathrm{a}_{3}$ & $\mathrm{CB}_{8}$ trip \\
\hline $\mathrm{a}_{4}$ & $\mathrm{CB}_{12}$ trip \\
\hline $\mathrm{a}_{5}$ & Failure protection $\mathrm{B}_{3}$ action \\
\hline $\mathrm{a}_{6}$ & $\mathrm{CB}_{13}$ trip \\
\hline $\mathrm{a}_{7}$ & $\mathrm{~T}_{3}$ far backup protection action \\
\hline $\mathrm{a}_{8}$ & $\mathrm{~T}_{4}$ far backup protection action \\
\hline $\mathrm{a}_{9}$ & $\mathrm{~L}_{5}$ far backup protection action \\
\hline $\mathrm{a}_{10}$ & $\mathrm{CB}_{15}$ trip \\
\hline $\mathrm{a}_{11}$ & $\mathrm{CB}_{14}$ trip \\
\hline $\mathrm{a}_{12}$ & $\mathrm{CB}_{32}$ trip \\
\hline
\end{tabular}

the IFTPN fault diagnosis model is established. The fault diagnosis process is shown in Figure 3 and is divided into five parts: (1) the search and establishment of fault areas; (2) the similarity matching of the time series; (3) the evaluation of the action for the protection and the action of the circuit breaker; (4) the establishment of the fault diagnosis model;

(5) the matrix deduction of fault cases.

The specific steps are as follows.

(1) After the grid fault occurs, according to the data information uploaded to the system, the fault area is first searched, then the suspected fault component is searched, and finally the suspicious fault component set is constructed.

(2) According to the principle of relay protection setting, a protection model is constructed for the protection device of the suspected faulty component to form a set of alarm hypothesis time series.
(3) The distance (Edit Distance and DTW Distance) between each time subsequence in the alarm hypothesis time series set and the alarm information sequence, received by the system center, are calculated by timing matching.

(4) The confidence level of the component protection action value is obtained by timing matching, and the state of the protection device that does not meet the time series matching is evaluated, including the action state of the protection and circuit breaker (rejection, misoperation, and information loss) and the time-scale accuracy of the alarm information (time-scale deviation and timing chaos).

(5) The IFTPN grid fault diagnosis model is established. The probability value of the initial library is corrected by the confidence of the protection and circuit breaker action. The inference algorithm is formed according to the intuitionistic fuzzy Petri Nets model, and the forward deduction is performed in the form of a matrix. Then, the fault probability value of the component is obtained.

\section{Case Simulation}

5.1. Case 1. In order to describe the entire reasoning process, the number of pieces of fault information is shown in Table 4, and the alarm information, with time stamps, is shown in Table 5. The sequence based on the case failure alert information is $X=\left\{x_{1}, x_{2}, x_{3}, \ldots, x_{11}\right\}$.

(1) Lines $L_{2}, L_{5}$, and Busbar $B_{3}$ search for the fault area according to the alarm information sequence to determine possible faulty elements.

(2) Since the information cannot be uploaded when the line, Busbar, and circuit breaker are faulty, the corresponding time-scale information is defined as a fuzzy item. According to the general model of the protection configuration, the time series inference rules and the time series of the alarm 
TABLE 5: Actual alarm information.

\begin{tabular}{lcc}
\hline Time series set & Alert message content & Time series number \\
\hline$\left(\left(\mathrm{a}_{1}, 0,1\right), 435\right)$ & $\mathrm{L}_{2}$ sending end main protection action & $x_{1}$ \\
\hline$\left(\left(\mathrm{a}_{2}, 0,1\right), 436\right)$ & $\mathrm{L}_{2}$ receiving end main protection action & $x_{2}$ \\
\hline$\left(\left(\mathrm{a}_{3}, 0,1\right), 460\right)$ & $\mathrm{CB}_{8}$ trip & $x_{3}$ \\
\hline$\left(\left(\mathrm{a}_{5}, 0,1\right), 740\right)$ & Failure protection $\mathrm{B}_{3}$ action & $x_{4}$ \\
\hline$\left(\left(\mathrm{a}_{6}, 0,1\right), 766\right)$ & $\mathrm{CB}_{13}$ trip & $x_{5}$ \\
\hline$\left(\left(\mathrm{a}_{7}, 0,1\right), 936\right)$ & $\mathrm{T}_{3}$ far backup protection action & $x_{6}$ \\
\hline$\left(\left(\mathrm{a}_{8}, 0,1\right), 937\right)$ & $\mathrm{T}_{4}$ far backup protection action & $x_{7}$ \\
\hline$\left(\left(\mathrm{a}_{9}, 0,1\right), 938\right)$ & $\mathrm{L}_{5}$ far backup protection action & $x_{8}$ \\
\hline$\left(\left(\mathrm{a}_{10}, 0,1\right), 961\right)$ & $\mathrm{CB}_{15}$ trip & $x_{9}$ \\
\hline$\left(\left(\mathrm{a}_{11}, 0,1\right), 963\right)$ & $\mathrm{CB}_{14}$ trip & $x_{10}$ \\
\hline$\left(\left(\mathrm{a}_{12}, 0,1\right), 973\right)$ & $\mathrm{CB}_{32}$ trip & $x_{11}$ \\
\hline
\end{tabular}

TABLE 6: Failure collection.

\begin{tabular}{lc}
\hline $\begin{array}{l}\text { Transmission } \\
\text { line } \mathrm{L}_{2}\end{array}$ & $\begin{array}{c}\left\{\mathrm{a}_{1}, \mathrm{a}_{3}\right\},\left\{\mathrm{a}_{2}, \mathrm{a}_{4}, \mathrm{a}_{5}, \mathrm{a}_{6}\right\},\left\{\mathrm{a}_{2}, \mathrm{a}_{4}, \mathrm{a}_{5}, \mathrm{a}_{8}, \mathrm{a}_{10}\right\}, \\
\left.\left\{\mathrm{a}_{2}, \mathrm{a}_{4}, \mathrm{a}_{5}, \mathrm{a}_{7}, \mathrm{a}_{11}\right\},\left\{\mathrm{a}_{2}, \mathrm{a}_{4}, \mathrm{a}_{5}, \mathrm{a}_{9}, \mathrm{a}_{12}\right\}\right\}\end{array}$ \\
\hline $\begin{array}{l}\text { Transmission } \\
\text { line } \mathrm{L}_{5}\end{array}$ & $\left\{\mathrm{a}_{12}\right\}$ \\
\hline Busbar $\mathrm{B}_{3}$ & $\left\{\mathrm{a}_{5}, \mathrm{a}_{6}\right\}$ \\
\hline
\end{tabular}

information, a time series hypothesis set for the failed component, and the values of $\mathrm{a}$ and $\mathrm{b}$ are both 5 . The fault set of Busbar $B_{3}$ and lines $L_{2}, L_{5}$ is shown in Table 6 .

(3) In the case of complex faults, the protection and circuit breaker only act in response to one faulty component. In this case, the fault set of line $\mathrm{L}_{2}$ covers the fault set of line $L_{5}$ and Busbar $B_{3}$, and then the fault analysis of line $L_{2}$ is prioritized. The initial place reliability of the circuit breakers of the line $\mathrm{L}_{5}$ protection configuration, of the protection of the Busbar $\mathrm{B}_{3}$, and of the circuit breakers corresponding to the Busbar $B_{3}$ protection is corrected to $(0.19666,0.03147)$, $(0.17128,0.0579)$, and $(0.16666,0.04825)$, respectively.

(4) Taking line $\mathrm{L}_{2}$ as an example, the time series confidence of the faulty component is calculated, as shown in Table 7, and it is used to correct the value of the initial place. Through the analysis of the time series, $\mathrm{CB}_{12}$ is refused. The maximum six propagation directions for the fault of line $\mathrm{L}_{2}$ are $\left(\mathrm{B}_{3}, \mathrm{CB}_{13}\right),\left(\mathrm{T}_{3}, \mathrm{CB}_{14}\right),\left(\mathrm{T}_{4}, \mathrm{CB}_{15}\right),\left(\mathrm{L}_{5}, \mathrm{CB}_{32}\right),\left(\mathrm{B}_{2}, \mathrm{CB}_{6}\right)$, and $\left(\mathrm{L}_{4}, \mathrm{CB}_{27}\right)$.

According to the alarm information, four determined fault propagation directions are obtained and modeled separately. The intuitive fuzzy Petri Nets fault diagnosis model for line $\mathrm{L}_{2}$ is shown in Figure 7. Taking the receiving end of line $\mathrm{L}_{2}$ as an example in the direction of $\mathrm{L}_{5}$ propagation, matrix reasoning is performed on the fault confidence of line $\mathrm{L}_{2}$. (1) Input Matrix I with Weights

$$
I=\left[\begin{array}{cccccccccc}
0.5 & 0.5 & 0 & 0 & 0 & 0 & 0 & 0 & 0 & 0 \\
0 & 0 & 0.5 & 0.5 & 0 & 0 & 0 & 0 & 0 & 0 \\
0 & 0 & 0 & 0 & 0.5 & 0.5 & 0 & 0 & 0 & 0 \\
0 & 0 & 0 & 0 & 0 & 0 & 1 & 0 & 0 & 0 \\
0 & 0 & 0 & 0 & 0 & 0 & 0 & 1 & 0 & 0 \\
0 & 0 & 0 & 0 & 0 & 0 & 0 & 0 & 1 & 0
\end{array}\right]
$$

(2) Output Matrix O with Confidence

$$
O=\left[\begin{array}{cccccccccc}
(0,1) & (0,1) & (0,1) & (0,1) & (0,1) & (0,1) & (1,0) & (0,1) & (0,1) & (0,1) \\
(0,1) & (0,1) & (0,1) & (0,1) & (0,1) & (0,1) & (0,1) & (1,0) & (0,1) & (0,1) \\
(0,1) & (0,1) & (0,1) & (0,1) & (0,1) & (0,1) & (0,1) & (0,1) & (1,0) & (0,1) \\
(0,1) & (0,1) & (0,1) & (0,1) & (0,1) & (0,1) & (0,1) & (0,1) & (0,1) & (0.95,0.025) \\
(0,1) & (0,1) & (0,1) & (0,1) & (0,1) & (0,1) & (0,1) & (0,1) & (0,1) & (0.95,0.025) \\
(0,1) & (0,1) & (0,1) & (0,1) & (0,1) & (0,1) & (0,1) & (0,1) & (0,1) & (0.95,0.025)
\end{array}\right]
$$

\section{(3) Transition Threshold Matrix}

$$
\Gamma=[(0.2,0.7),(0.2,0.7),(0.2,0.7),(0.2,0.7),(0.2,0.7) \text {, }
$$

(4) The Fuzzy Value Matrix of the Initial Place

$\mathrm{M}_{0}=[(0.9913,0.006294),(0.19666,0.03094)$,

$(0.7930,0.007868),(0.16716,0.0364)$, 
TABLE 7: The calculation of time series confidence.

\begin{tabular}{|c|c|c|c|c|}
\hline Alarm hypothesis time series & ED & $\mathrm{TD}$ & TOD & TSC \\
\hline$\left\{\left(\left(a_{1}, 10,1\right), 435\right),\left(\left(a_{3}, 10,1\right), 460\right)\right\}$ & 0 & 0 & 0 & 1 \\
\hline$\left\{\left(\left(\mathrm{a}_{2}, 10,1\right), 436\right),\left(\left(\mathrm{a}_{4}, 10,1\right), 461\right)\right\}$ & 1 & 0 & 5 & 0.2 \\
\hline $\begin{array}{l}\left\{\left(\left(\mathrm{a}_{2}, 10,1\right), 436\right),\left(\left(\mathrm{a}_{4}, 10,0\right), 461\right),\right. \\
\left.\left(\left(\mathrm{a}_{5}, 10,1\right), 740\right),\left(\left(\mathrm{a}_{6}, 0,1\right), 765\right)\right\}\end{array}$ & 0 & 0 & 0 & 1 \\
\hline $\begin{array}{l}\left\{\left(\left(a_{2}, 10,1\right), 436\right),\left(\left(a_{4}, 10,0\right), 461\right),\right. \\
\left(\left(a_{5}, 10,1\right), 740\right),\left(\left(a_{7}, 0,1\right), 936\right), \\
\left.\left(\left(a_{11}, 0,1\right), 961\right)\right\}\end{array}$ & 0 & 0 & 0 & 1 \\
\hline $\begin{array}{l}\left\{\left(\left(a_{2}, 10,1\right), 436\right),\left(\left(a_{4}, 10,0\right), 461\right),\left(\left(a_{5},\right.\right.\right. \\
10,1), 740),\left(\left(a_{8}, 10,1\right), 937\right),\left(\left(a_{10}, 0,1\right),\right. \\
962)\}\end{array}$ & 0 & 0 & 0 & 1 \\
\hline $\begin{array}{l}\left\{\left(\left(a_{2}, 10,1\right), 436\right),\left(\left(a_{4}, 10,0\right), 461\right),\left(\left(a_{5},\right.\right.\right. \\
10,1), 691),\left(\left(a_{9}, 10,1\right), 938\right),\left(\left(a_{12}, 10,1\right),\right. \\
963)\}\end{array}$ & 0 & 0 & 0 & 1 \\
\hline
\end{tabular}

ED: Edit Distance; TD: DTW Distance; TOD: total distance;

TSC: time series confidence.

$(0.6939,0.008991),(0.7375,0.008251),(0,1),(0,1)$,

Derived by algorithm,

$(0,1),(0,1)]$

$$
\begin{aligned}
& \mathrm{M}_{1}=[(0.9913,0.006294),(0.19666,0.03094),(0.7930,0.007868),(0.16716,0.0364) \\
& \quad(0.6939,0.008991)(0.7375,0.008251),(0.59398,0.018617),(0.48008,0.022134),(0.7157,0.008621),(0,1)] \\
& M_{2}=[(0.9913,0.006294),(0.19666,0.03094),(0.7930,0.007868),(0.16716,0.0364),(0.6939,0.008991) \\
& \quad(0.7375,0.008251),(0.59398,0.018617),(0.48008,0.022134),(0.7157,0.008621),(0.7454,0.008351)] \\
& M_{3}=[(0.9913,0.006294),(0.19666,0.03094),(0.7930,0.007868),(0.16716,0.0364),(0.6939,0.008991) \\
& \quad(0.7375,0.008251),(0.59398,0.018617),(0.48008,0.022134),(0.7157,0.008621),(0.7454,0.008351)]
\end{aligned}
$$

When $\mathrm{M}_{3}=\mathrm{M}_{2}$, the inference calculation ends. The value of the fuzzy confidence of line $\mathrm{L}_{2}$ in the direction in which line $\mathrm{L}_{5}$ propagates is $(0.7454,0.008351)$; that is, the degree of certainty of line $\mathrm{L}_{2}$ in the direction in which line $\mathrm{L}_{5}$ propagates is 0.7454 , and the degree of uncertainty is 0.008351 . According to the metric function formula, the fault probability of line $\mathrm{L}_{2}$ is $F\left(L_{2 t 5}\right)=0.9888$. Similarly, the probability of failure in other propagation directions is $F\left(L_{2 t 3}\right)=0.9882, F\left(L_{2 t 4}\right)=0.9882$, and $F\left(L_{2 B 3}\right)=0.9869$.

A comparison curve, before and after data optimization, is shown in Figure 4.

Figure 4 shows a comparison of raw data values and optimized values between 0 and 1 . If the certainty of the fault value is in $(0.078135,1)$, it will be optimized. Conversely, if it is in $(0,0.078135)$, no processing will be done. Taking the data point 0.561146 as the fault distinguishing point, it can be clearly seen from the Figure 4 that the fault discrimination degree of the data after optimization is significantly higher than the raw data. In Figure 4, the intersections of the four lines perpendicular to the $\mathrm{x}$-axis and the two curves are a comparison of the raw data and the optimized data in Case
1. From the comparison results of each set of data in the figure, the method can improve the accuracy of the fault diagnosis results in line with expectations. In the direction of the sending end, the fault confidence of line $\mathrm{L}_{2}$ is $F\left(\mathrm{~L}_{2 \mathrm{CB}_{8}}\right)=$ 0.96725 .

In summary, the final failure probability value of line $\mathrm{L}_{2}$ is $F\left(\mathrm{~L}_{2}\right)=0.9776$, and it is determined, by $F\left(\mathrm{~L}_{2}\right)>\theta$, that $\mathrm{L}_{2}$ is the faulty item.

5.2. Case 2. In order to describe the entire reasoning process, the number of pieces of fault information is shown in Table 8, and the alarm information, with time stamps, is shown in Table 9. The sequence based on the case failure alert information is $X=\left\{x_{1}, x_{2}, x_{3}, \ldots, x_{10}\right\}$.

(1) Searching for the fault area, based on the alarm information received after the fault occurs, the suspect faulty component is determined as line $\mathrm{L}_{8}$, Busbar $\mathrm{B}_{7}$, and line $\mathrm{L}_{6}$.

(2) According to the general protection configuration model and the timing matching rule, the alarm hypothesis time series is generated for the protection of each suspicious component and the corresponding circuit breaker. The 


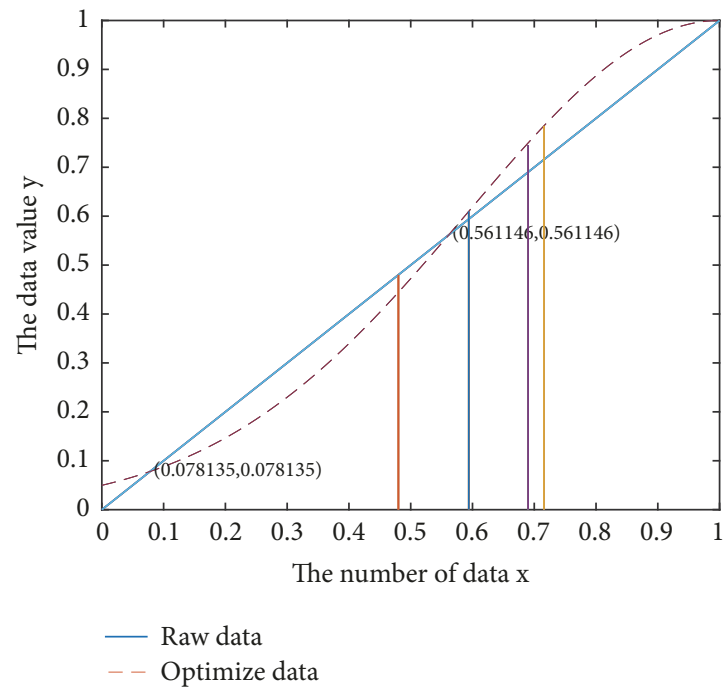

FIgURE 4: Data optimization comparison curve.

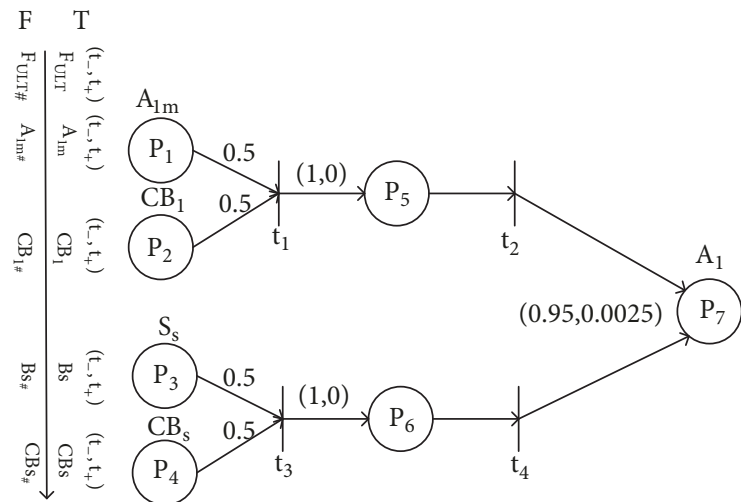

(a) Universal subnet diagnostic model

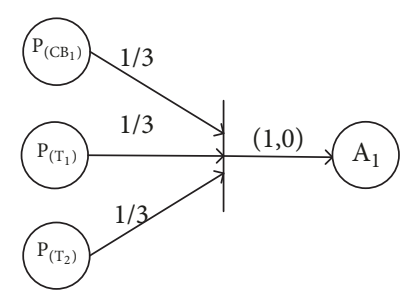

(b) Comprehensive diagnostic model

Figure 5: Single bus $B_{1}$ fault diagnosis model.

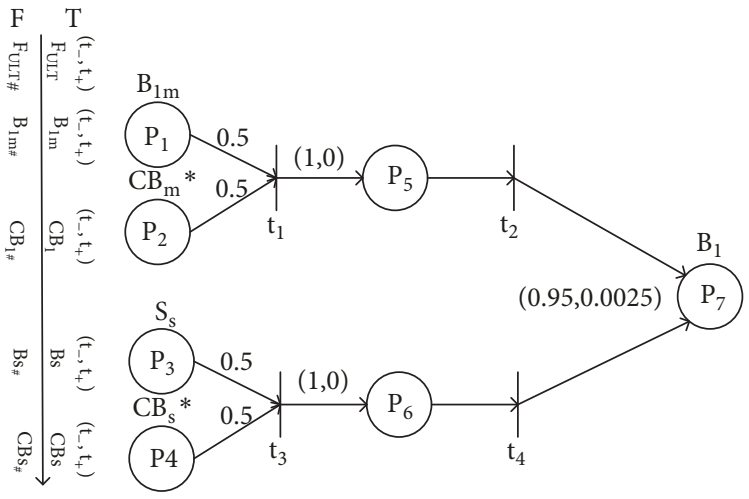

(a) Subnet diagnostic model of $B_{1}$

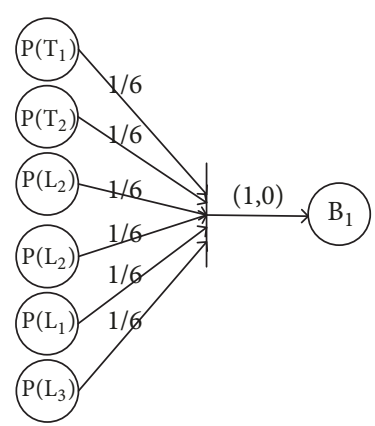

(b) $\mathrm{B}_{1}$ comprehensive diagnosis model

Figure 6: Double bus $B_{1}$ fault diagnosis model. 


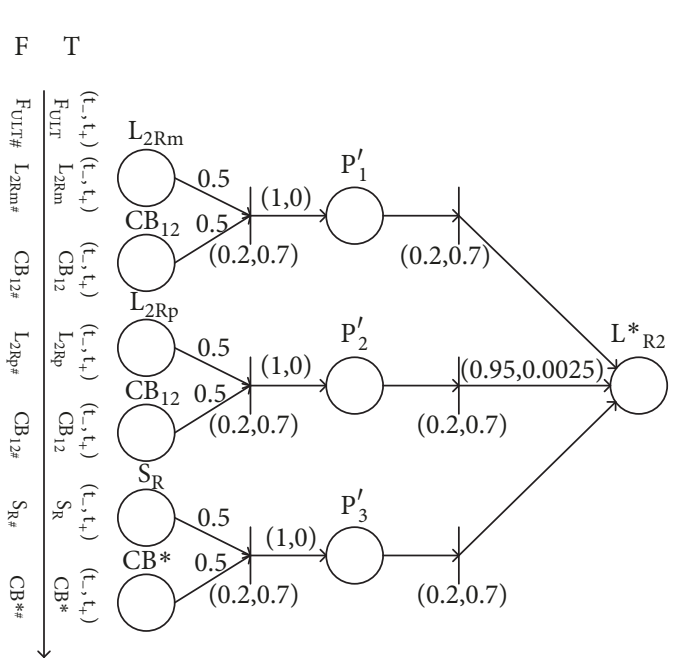

(a) Line $L_{2}$ receiving end single direction diagnostic model

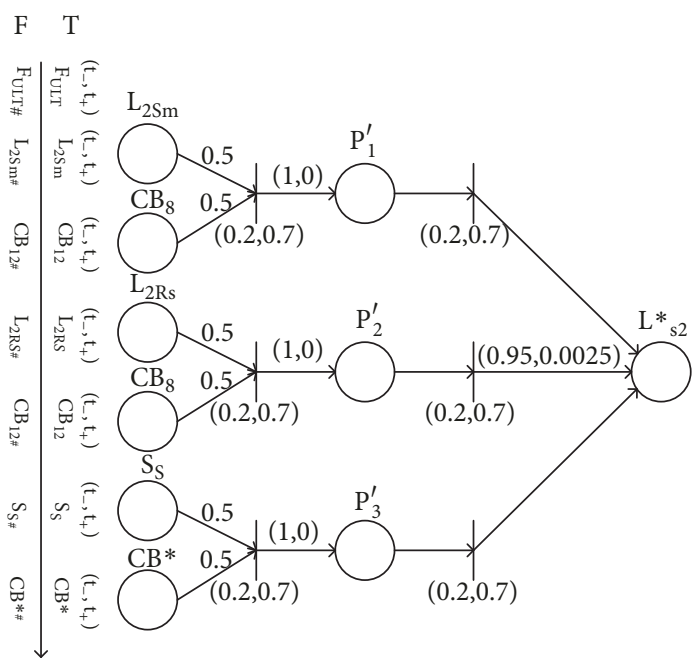

(b) Line $\mathrm{L}_{2}$ sending end single direction diagnostic model

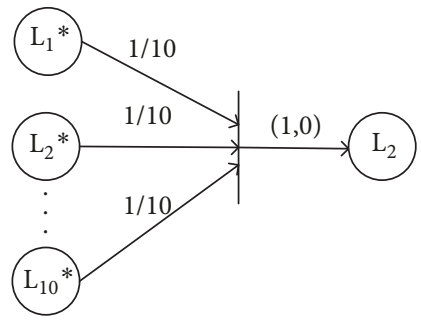

(c) Second layer diagnostic model

FIGURE 7: Line $\mathrm{L}_{2}$ fault comprehensive diagnosis model.

components related to line $\mathrm{L}_{8}$ are $\mathrm{L}_{8}$ sending end main protection, $\mathrm{CB}_{30}$ circuit breaker, and $\mathrm{CB}_{40}$ circuit breaker. The components related to Busbar $B_{7}$ are $B_{7}$ main protection, $\mathrm{CB}_{34}$ circuit breaker, $\mathrm{CB}_{35}$ circuit breaker, $\mathrm{CB}_{33}$ circuit breaker, $\mathrm{L}_{6}$ transmission end remote backup protection, and $\mathrm{CB}_{20}$ circuit breaker. The components related to line $\mathrm{L}_{6}$ are $\mathrm{L}_{6}$ sending end remote backup protection and $\mathrm{CB}_{20}$ circuit breaker. The hypothetical time series of the corresponding suspicious elements can be constructed according to the fault set in Table 10.

(3) The distance between the hypothesis time and the actual alarm time series of all fault sets of line $\mathrm{L}_{6}$, line $\mathrm{L}_{8}$, and Busbar $\mathrm{B}_{7}$ are calculated and then converted into timing confidence, wherein the default value of parameters $a$ and $b$ is 5. Table 11 is the total distance and the timing confidence after correction, and the reason for the correction is described in step (4).

(4) The time series confidence is calculated according to (4), as shown in Table 11. The probability values of the initial library are weighted using time series confidence. According to the timing matching, the main protection of the line $\mathrm{L}_{8}$ transmitter is matched with the $\mathrm{CB}_{30}$ circuit breaker. The $\mathrm{B}_{7}$ main protection is matched with the $\mathrm{CB}_{34}$ circuit breaker, $\mathrm{CB}_{35}$ circuit breaker, and $\mathrm{CB}_{33}$ circuit breaker and is matched with the line $\mathrm{L}_{6}$ sending end backup protection and $\mathrm{CB}_{20}$ circuit breaker. The terminal primary protection information of line $\mathrm{L}_{8}$ is missing, because the $\mathrm{CB}_{40}$ circuit breaker trip
TABLE 8: The code of alarm information.

\begin{tabular}{lc}
\hline Number & Fault type \\
\hline $\mathrm{a}_{1}$ & $\mathrm{~L}_{8}$ sending end main protection action \\
\hline $\mathrm{a}_{2}$ & $\mathrm{CB}_{30}$ trip \\
\hline $\mathrm{a}_{3}$ & $\mathrm{CB}_{40}$ trip \\
\hline $\mathrm{a}_{4}$ & $\mathrm{~B}_{7}$ main protection action \\
\hline $\mathrm{a}_{5}$ & $\mathrm{CB}_{34}$ trip \\
\hline $\mathrm{a}_{6}$ & $\mathrm{CB}_{35}$ trip \\
\hline $\mathrm{a}_{7}$ & $\mathrm{CB}_{33}$ trip \\
\hline $\mathrm{a}_{8}$ & $\mathrm{~L}_{6}$ send end far backup action \\
\hline $\mathrm{a}_{9}$ & $\mathrm{CB}_{20}$ trip \\
\hline $\mathrm{a}_{10}$ & $\mathrm{CB}_{29}$ trip \\
\hline $\mathrm{a}_{11}$ & $\mathrm{~L}_{8}$ receiving end main protection \\
\hline $\mathrm{a}_{12}$ & $\mathrm{CB}_{31}$ trip
\end{tabular}

does not satisfy the time-scale matching of the fault set of Busbar $\mathrm{B}_{7}$ but matches the time-scale of the line $\mathrm{L}_{8}$ receiving end main protection. Therefore, it is determined that the information of the primary protection of the receiving end of $\mathrm{L}_{8}$ is lost. The circuit breaker $\mathrm{CB}_{31}$ of the main protection of Busbar $\mathrm{B}_{7}$ refuses to operate, and the far-end backup operation of line $\mathrm{L}_{6}$ causes the $\mathrm{CB}_{20}$ circuit breaker to trip, which satisfies the timing matching of Busbar $B_{7}$ in the line $\mathrm{L}_{6}$ fault propagation direction. 
TABLE 9: Actual alarm information.

\begin{tabular}{lcc}
\hline Time series set & Alert message content & $\begin{array}{c}\text { Time series } \\
\text { number }\end{array}$ \\
\hline$\left(\left(\mathrm{a}_{1}, 0,1\right), 05: 315\right)$ & $\begin{array}{c}\mathrm{L}_{8} \text { sending end main } \\
\text { protection action }\end{array}$ & $x_{1}$ \\
\hline$\left(\left(\mathrm{a}_{2}, 0,1\right), 05: 344\right)$ & $\mathrm{CB}_{30}$ trip & $x_{2}$ \\
\hline$\left(\left(\mathrm{a}_{3}, 0,1\right), 05: 345\right)$ & $\mathrm{CB}_{40}$ trip & $x_{3}$ \\
\hline$\left(\left(\mathrm{a}_{4}, 0,1\right), 06: 315\right)$ & $\mathrm{B}_{7}$ main protection action & $x_{4}$ \\
\hline$\left(\left(\mathrm{a}_{5}, 0,1\right), 06: 343\right)$ & $\mathrm{CB}_{34}$ trip & $x_{5}$ \\
\hline$\left(\left(\mathrm{a}_{6}, 0,1\right), 05: 327\right)$ & $\mathrm{CB}_{35}$ trip & $x_{6}$ \\
\hline$\left(\left(\mathrm{a}_{7}, 0,1\right), 06: 352\right)$ & $\mathrm{CB}_{33}$ trip & $x_{7}$ \\
\hline$\left(\left(\mathrm{a}_{8}, 0,1\right), 06: 824\right)$ & $\mathrm{L}_{6}$ send end far backup & $x_{8}$ \\
\hline$\left(\left(\mathrm{a}_{9}, 0,1\right), 06: 846\right)$ & $\mathrm{action}$ & $x_{9}$ \\
\hline$\left(\left(\mathrm{a}_{10}, 0,1\right), 08: 100\right)$ & $\mathrm{CB}_{20}$ trip & $x_{10}$ \\
\hline
\end{tabular}

TABLE 10: Failure collection.

\begin{tabular}{lc}
\hline Transmission & $\left(\left\{\left\{\left(\left(\mathrm{a}_{1}, 10,1\right), 05: 315\right)\right\},\left\{\left(\left(\mathrm{a}_{2}, 10,1\right), 05: 344\right)\right\}\right.\right.$, \\
line $\mathrm{L}_{8}$ & $\left.\left.\left\{\left(\left(\mathrm{a}_{11}, 10,0\right), 05: 315\right)\right\},\left\{\left(\left(\mathrm{a}_{3}, 10,1\right), 05: 345\right)\right\}\right\}\right)$ \\
\hline & $\left(\left(\left(\mathrm{a}_{4}, 10,1\right), 06: 315\right),\left\{\left\{\left\{\left(\left(\mathrm{a}_{5}, 10,1\right), 06: 343\right)\right\}\right.\right.\right.$, \\
Busbar $\mathrm{B}_{7}$ & $\left\{\left(\left(\mathrm{a}_{6}, 10,1\right), 05: 327\right)\right\},\left\{\left(\left(\mathrm{a}_{7}, 10,1\right), 06: 352\right)\right\}$, \\
& $\left.\left\{\left(\left(\mathrm{a}_{3}, 0,1\right), 05: 345\right)\right\}\right\},\left\{\left\{\left(\left(\mathrm{a}_{12}, 10,0\right), 06: 344\right)\right\}\right.$, \\
& $\left.\left.\left.\left\{\left(\left(\mathrm{a}_{8}, 10,0\right), 06: 824\right)\right\},\left\{\left(\left(\mathrm{a}_{9}, 10,0\right), 06: 846\right)\right\}\right\}\right\}\right)$ \\
\hline Transmission & $\left\{\left(\left(\mathrm{a}_{8}, 0,1\right), 06: 824\right)\right\},\left\{\left(\left(\mathrm{a}_{9}, 0,1\right), 06: 846\right)\right\}$ \\
line $\mathrm{L}_{6}$ & \\
\hline
\end{tabular}

TABLE 11: The calculation of time series confidence.

\begin{tabular}{|c|c|c|c|c|c|}
\hline $\begin{array}{l}\text { Alarm hypothesis time } \\
\text { series }\end{array}$ & & $\mathrm{ED}$ & $\mathrm{TD}$ & TOD & TSC \\
\hline $\begin{array}{l}\left\{\left(\left(\mathrm{a}_{1}, 10,1\right), 05:\right.\right. \\
\left.315),\left(\left(\mathrm{a}_{2}, 10,1\right), 05: 344\right)\right\}\end{array}$ & $\mathrm{L}_{8}$ & 0 & 0 & 0 & 1 \\
\hline $\begin{array}{l}\left\{\left(\left(\mathrm{a}_{11}, 10,0\right), 05:\right.\right. \\
\left.315),\left(\left(\mathrm{a}_{3}, 10,1\right), 05: 345\right)\right\}\end{array}$ & & 1 & 0 & 5 & 0.2 \\
\hline $\begin{array}{l}\left\{\left(\left(\mathrm{a}_{4}, 10,1\right), 06:\right.\right. \\
\left.315),\left(\left(\mathrm{a}_{5}, 10,1\right), 06: 343\right)\right\}\end{array}$ & & 0 & 0 & 0 & 1 \\
\hline $\begin{array}{l}\left\{\left(\left(\mathrm{a}_{4}, 10,1\right), 06:\right.\right. \\
\left.315),\left(\left(\mathrm{a}_{6}, 10,1\right), 05: 327\right)\right\}\end{array}$ & & 0 & 1 & 1 & 1 \\
\hline $\begin{array}{l}\left\{\left(\left(\mathrm{a}_{4}, 10,1\right), 06:\right.\right. \\
\left.315),\left(\left(\mathrm{a}_{7}, 10,1\right), 06: 352\right)\right\}\end{array}$ & $\mathrm{B}_{7}$ & 0 & 0 & 0 & 1 \\
\hline $\begin{array}{l}\left\{\left(\left(\mathrm{a}_{4}, 10,1\right), 06:\right.\right. \\
\left.315),\left(\left(\mathrm{a}_{3}, 0,1\right), 05: 345\right)\right\}\end{array}$ & $\mathrm{D}_{7}$ & 0 & 1 & 1 & 1 \\
\hline $\begin{array}{l}\left\{\left(\left(\mathrm{a}_{4}, 10,1\right), 06:\right.\right. \\
\left.315),\left(\left(\mathrm{a}_{12}, 10,0\right), 06: 344\right)\right\}\end{array}$ & & 1 & 0 & 5 & 0.2 \\
\hline $\begin{array}{l}\left\{\left(\left(\mathrm{a}_{4}, 10,1\right), 06:\right.\right. \\
\left.315)\left(\left(\mathrm{a}_{8}, 10,0\right), 06: 824\right)\right\} \\
\left\{\left(\left(\mathrm{a}_{9}, 10,0\right), 06: 846\right)\right\}\end{array}$ & & 0 & 0 & 0 & 1 \\
\hline $\begin{array}{l}\left\{\left(\left(\mathrm{a}_{8}, 0,1\right), 06: 824\right)\right\} \\
\left\{\left(\left(\mathrm{a}_{9}, 0,1\right), 06: 846\right)\right\}\end{array}$ & $\mathrm{L}_{6}$ & 1 & 1 & 10 & 0.1 \\
\hline
\end{tabular}

ED: Edit Distance; TD: DTW Distance; TOD: total distance;

TSC: time series confidence.

The circuit breaker $\mathrm{CB}_{29}$ has no relevant components to form a sequence with it, and the difference between the time stamps of other components is large, so $\mathrm{CB}_{29}$ is judged to be malfunctioning.
The $\mathrm{CB}_{40}$ circuit breaker exists in both the fault set of line $\mathrm{L}_{8}$ and the fault set of Busbar $\mathrm{B}_{7}$. Since $\mathrm{CB}_{40}$ satisfies the protection action time sequence of line $\mathrm{L}_{8}$ and operates accurately, the $\mathrm{CB}_{40}$ circuit breaker should be within the fault set of line $\mathrm{L}_{8}$. According to the fault sets of Busbar $B_{7}$, the $\mathrm{CB}_{35}$ circuit breaker should act on the fault of Busbar $\mathrm{B}_{7}$, and the circuit breaker $\mathrm{CB}_{35}$ also does not satisfy the fault sets of other components. Thus, the error of the $\mathrm{CB}_{35}$ circuit breaker time mark in the Busbar $B_{7}$ fault sets can be judged. Therefore, the weights of the time distances of the $\mathrm{CB}_{40}$ circuit breaker and the $\mathrm{CB}_{35}$ circuit breaker in the Busbar $\mathrm{B}_{7}$ fault sets should be corrected. In (4), the weights $a$ and $b$ are corrected to $a=9$ and $b=1$. The total distance of Busbar protection in this direction is 1 . The initial probability values of the protection and circuit breakers are corrected using the time series confidence obtained.

Line $\mathrm{L}_{6}$ does not satisfy the timing matching, and the failure probability can be directly considered as time series confidence $\mathrm{P}\left(\mathrm{L}_{6}\right)=0.1$.

(5) According to the IFTPN model inference algorithm, the confidence degree of the final line can be obtained. The fault of line $\mathrm{L}_{8}$ is $\mathrm{P}\left(\mathrm{L}_{8}\right)=0.96723$, and the probability of the failure of Busbar $B_{7}$ is $P\left(B_{7}\right)=0.9975$.

The obtained data results are compared with study [24] in relation to the same faulty case. As shown in Table 1, the failure probability value of the component that should be faulted is significantly increased, and the failure probability value of the nonfaulty component is significantly reduced.

According to the reasoning process and the comparison in Table 1, the IFTPN grid fault diagnosis model, established in this paper, can accurately solve many complicated situations, such as timing chaos, protection, circuit breaker refusal, misoperation, and information loss. The results show that the probability of the failure of the same component is more accurate under the same fault condition (the failure probability of the faulty component is greater, and the probability of the failure of the nonfaulty component is smaller).

The fault diagnosis results, obtained by the method presented in this paper, through line $\mathrm{L}_{0407}$ in study [27], are shown in Table 2. Compared to the original method, the method proposed in this paper effectively improves the accuracy of fault diagnosis. A comparison of the grid fault diagnosis method, proposed in this paper, and the other three grid fault diagnosis methods is shown in Table 3. The proposed method has a better fault tolerance performance, higher accuracy of diagnosis results, and faster diagnosis speed.

\section{Conclusion}

(1) For uncertain and incomplete information in power grids, we propose the IFTPN fault diagnosis model in this paper. The influence of the combination of the intuitionistic fuzzy algorithm and Petri Nets on the fault diagnosis results is explored. The results show that the model can still make a rapid and effective diagnosis of power system faults, when the information is incomplete.

(2) In order to make full use of the alarm information, we introduce the concept of timing matching into the 
intuitionistic fuzzy Petri Nets for grid fault diagnosis. The initial place data are corrected by timing confidence, and the case deduction shows that the diagnosis results are more accurate.

(3) In this paper, the degrees of certainty and uncertainty in the intuitionistic fuzzy algorithm are separately optimized in the calculation process. The optimization curve shows that the method improves the accuracy and reliability of fault diagnosis. In future work, we will research the electrical quantity itself and the effect of the time-constrained relationship between electrical quantity and component action on the diagnostic results.

\section{Appendix}

\section{A.}

(1) The IFTPN fault diagnosis model of the single Busbar $A_{1}$ is shown in Figure 5, and (a) is the subnet diagnostic model and (b) is the comprehensive diagnostic model. The sequence is $\left\{\left(\mathrm{A}_{1 \mathrm{~m}}, \mathrm{CB}_{1}, \mathrm{Ss}, \mathrm{CB}_{1}\right) ;\left(\mathrm{A}_{1 \mathrm{~m}}, \mathrm{CB}_{2}, \mathrm{~T}_{1 \mathrm{~s}}, \mathrm{CB}_{2}\right) ;\left(\mathrm{A}_{1 \mathrm{~m}}, \mathrm{CB}_{3}, \mathrm{~T}_{2 \mathrm{~s}}\right.\right.$, $\left.\left.\mathrm{CB}_{3}\right)\right\}$.

(2) IFTPN fault diagnosis model of double Busbar $B_{1}$ is shown in Figure 6, and (a) is the subnet diagnosis model and (b) is the comprehensive diagnosis model. The sequence is $\left\{\left(\mathrm{B}_{1 \mathrm{~m}}, \mathrm{CB}_{4}, \mathrm{~T}_{1 \mathrm{~s}}, \mathrm{CB}_{4}\right) ;\left(\mathrm{B}_{1 \mathrm{~m}}, \mathrm{CB}_{5}, \mathrm{~T}_{2 \mathrm{~s}}, \mathrm{CB}_{5}\right) ;\left(\mathrm{B}_{1 \mathrm{~m}}, \mathrm{CB}_{6}, \mathrm{~L}_{2 \mathrm{Rs}}\right.\right.$, $\left.\mathrm{CB}_{12}\right) ;\left(\mathrm{B}_{1 \mathrm{~m}}, \mathrm{CB}_{6}, \mathrm{~L}_{4 \mathrm{Rs}}, \mathrm{CB}_{27}\right) ;\left(\mathrm{B}_{1 \mathrm{~m}}, \mathrm{CB}_{7}, \mathrm{~L}_{1 \mathrm{Rs}}, \mathrm{CB}_{11}\right) ;\left(\mathrm{B}_{1 \mathrm{~m}}\right.$, $\left.\mathrm{CB}_{9}, \mathrm{~L}_{3 R s}, \mathrm{CB}_{28}\right)$.

(3) The IFTPN fault diagnosis model of line L2 is shown in Figure 7, and (a) and (b) are the diagnostic model for the terminal network and (c) is the comprehensive diagnosis model. The sequence is $\left\{\left(\left\{\left\{\mathrm{L}_{2 \mathrm{Sm}}, \mathrm{CB}_{8}, \mathrm{~L}_{2 \mathrm{Sr}}, \mathrm{CB}_{8}\right\},\left\{\mathrm{T}_{1 \mathrm{~s}}, \mathrm{CB}_{4}\right\}\right.\right.\right.$, $\left.\left.\left\{\mathrm{T}_{2 \mathrm{~s}}, \mathrm{CB}_{5}\right\},\left\{\mathrm{L}_{\mathrm{Rs}}, \mathrm{CB}_{28}\right\},\left\{\mathrm{L}_{1 \mathrm{Rs}}, \mathrm{CB}_{11}\right\},\left\{\mathrm{L}_{4 \mathrm{Rs}}, \mathrm{CB}_{27}\right\}\right\}\right) ;\left(\left\{\left\{\mathrm{L}_{2 \mathrm{Rm}}\right.\right.\right.$, $\left.\mathrm{CB}_{12}, \mathrm{~L} 2_{\mathrm{Rr}}, \mathrm{CB}_{12}\right\},\left\{\mathrm{T}_{3 \mathrm{~s}}, \mathrm{CB}_{14}\right\},\left\{\mathrm{T}_{4 \mathrm{~s}}, \mathrm{CB}_{15}\right\},\left\{\mathrm{L}_{5 \mathrm{Rs}}, \mathrm{CB} 32\right\}$, $\left.\left.\left.\left\{\mathrm{L}_{1 \mathrm{Ss}}, \mathrm{CB}_{7}\right\},\left\{\mathrm{L}_{6 \mathrm{Rs}}, \mathrm{CB}_{31}\right\}\right\}\right)\right\}$.

\section{B.}

See Tables 4, 5, 6, 7, 8, 9, 10, and 11 .

\section{Data Availability}

The data used to support the findings of this study are available from the corresponding author upon request.

\section{Conflicts of Interest}

The authors declare that there are no conflicts of interest.

\section{Acknowledgments}

The Project was supported by the National Natural Science Foundation of China Program (no. 61503224), Shandong Natural Science Foundation of China (no. ZR2017MF048), Major Research Development Program of Shandong province of China (no. 2016GSF117009), and Qingdao Minsheng Science and Technology Plan Project (no. 17-3-3-88-Nash).

\section{References}

[1] F. Cheng, L. Qu, W. Qiao, C. Wei, and L. Hao, "Fault diagnosis of wind turbine gearboxes based on DFIG stator current envelope analysis," IEEE Transactions on Sustainable Energy, pp. 1-1, 2018.

[2] X. Bai, L. Qu, and W. Qiao, "Robust AC optimal power flow for power networks with wind power generation," IEEE Transactions on Power Systems, vol. 31, no. 5, pp. 4163-4164, 2016.

[3] R. Jia, F. Ma, J. Dang, G. Liu, and H. Zhang, "Research on multidomain fault diagnosis of large wind turbines under complex environment," Complexity, 2018.

[4] D. Ma, Y. Liang, X. Zhao, R. Guan, and X. Shi, "Multi-BP expert system for fault diagnosis of powersystem," Engineering Applications of Artificial Intelligence, vol. 26, no. 3, pp. 937-944, 2013.

[5] S. Chen, J. Xie, G. Bi, J. Zhang, W. Zhang, and C. Gao, "A novel two terminal fault location method used ANN for UHVDC transmission line," Transactions of China Electrotechnical Society, vol. 30, no. 4, pp. 257-264, 2015.

[6] A. F. Novelo, E. Q. Cucarella, E. G. Moreno, and F. M. Anglada, "Fault diagnosis of electric transmission lines using modular neural networks," IEEE Latin America Transactions, vol. 14, no. 8, pp. 3663-3668, 2016.

[7] M. Eliassi, A. K. Dashtaki, H. Seif, M.-R. Haghifam, and C. Singh, "Application of Bayesian networks in composite power system reliability assessment and reliability-based analysis," IET Generation, Transmission \& Distribution, vol. 9, no. 13, pp. 1755$1764,2015$.

[8] X. Luo and X. Tong, "Structure-variable bayesian network for power system fault diagnosis considering credibility," Power System Technology, vol. 39, no. 9, pp. 2658-2664, 2015.

[9] R. Ghimire, C. Zhang, and K. R. Pattipati, "A Rough set-theorybased fault-diagnosis method for an electric power-steering system," IEEE/ASME Transactions on Mechatronics, vol. 23, no. 5, pp. 2042-2053, 2018.

[10] X. Cheng, C. Wang, Y. Yu, L. Yi, and Q. Chen, "An approach for three-phase asynchronous motor failure analysis based on fuzzy fault Petri nets," Diangong Jishu Xuebao/Transactions of China Electrotechnical Society, vol. 30, no. 17, pp. 132-139, 2015.

[11] X. Cheng, Q. Chen, Y. Yu, C. Wang, and J. Liu, "A fault diagnosis approach of power networks based on maximum likelihood decoding petri net models," Diangong Jishu Xuebao/Transactions of China Electrotechnical Society, vol. 30, no. 15, pp. 46-52, 2015.

[12] L. Wang, Q. Chen, Z. Gao et al., "Knowledge representation and general Petri net models for power grid fault diagnosis, in IET generation," Transmission \& Distribution, vol. 9, no. 9, pp. 866873, 2015 (Arabic).

[13] J. Sun, S.-Y. Qin, and Y.-H. Song, "Fault diagnosis of electric power systems based on fuzzy Petri nets," IEEE Transactions on Power Systems, vol. 19, no. 4, pp. 2053-2059, 2004.

[14] Y. N. Wang, J. F. Ye, G. J. Xu, Q. M. Chen, H. Y. Li, and X. R. Liu, "Novel hierarchical fault diagnosis approach for smart power grid with information fusion of multi-data resources based on fuzzy petri net," in Proceedings of the 2014 IEEE International Conference on Fuzzy Systems (FUZZ-IEEE '14), pp. 1183-1189, July 2014

[15] Q. Chen, X. Cheng, J. Liu et al., "Failure analysis of WFPN network based on hierarchical transition," Transactions of China Electrotechnical Society, vol. 31, no. 15, pp. 125-135, 2016.

[16] J. Yang and Z. He, "Power system fault diagnosis approach based on time sequence fuzzy Petri net," Dianli Xitong 
Zidonghua/Automation of Electric Power Systems, vol. 35, no. 15, pp. 46-51, 2011.

[17] X. Cheng, X. Lin, C. Zhu, Q. Chen, and M. Cao, "A Method for fault diagnosis of fuzzy petri nets based on time series information," Transactions of China Electrotechnical Society, vol. 32, no. 14, pp. 229-237, 2017.

[18] W. Wu, F. Wen, Y. Xue et al., "A weighted fuzzy Petri nets based model with time-delay constraints for power system fault diagnosis employing Information from multiple sources," in Automation of Electric Power Systems, vol. 37, pp. 43-45, 2013.

[19] J. Li, X. Zhu, and X. Cheng, "Sensor fault diagnosis based on fuzzy neural petri net," Complexity, vol. 2018, Article ID 8261549, 11 pages, 2018.

[20] J. Zhong, Y. Zhang, F. Wen, and H. Zhu, "Transmission system fault diagnosis method based on time series similarity matching," in Automation of Electric Power Systems, vol. 39, pp. 60-67, 2015.

[21] J. Antucheviciene, M. Tavana, M. Nilashi, and R. Bausys, "Managing information uncertainty and complexity in decisionmaking," Complexity, Article ID 1268980, 3 pages, 2017.

[22] L. Zhihan, O. Kaoru, L. Jaime, X. Wei, and B. Paolo, "Complexity problems handled by big data technology," Complexity, Article ID 9090528, 7 pages, 2019.

[23] J. Yang, Z. He, and T. Zang, "Power system fault-diagnosis method based on directional weighted fuzzy petri nets," in Proceedings of the CSEE, vol. 30, pp. 42-49, 2010.

[24] X. Zhang, S. Yue, and X. Zha, "Method of power grid fault diagnosis using intuitionistic fuzzy Petri nets," IET Generation, Transmission \& Distribution, vol. 12, no. 2, pp. 295-302, 2018.

[25] H.-C. Liu, J.-X. You, X.-Y. You, and Q. Su, "Fuzzy petri nets using intuitionistic fuzzy sets and ordered weighted averaging operators," IEEE Transactions on Cybernetics, vol. 46, no. 8, pp. 1839-1850, 2016.

[26] Z. Ai, Z. Xu, and Q. Lei, "Fundamental properties with respect to the completeness of intuitionistic fuzzy partially ordered set," IEEE Transactions on Fuzzy Systems, vol. 25, no. 6, pp. 1741-1751, 2017.

[27] J. Chen, Research on Fault Diagnosis of Power System Uncertainty Based on Information Fusion, Southwest Jiaotong University, Chengdu, Sichuan, China, 2014. 


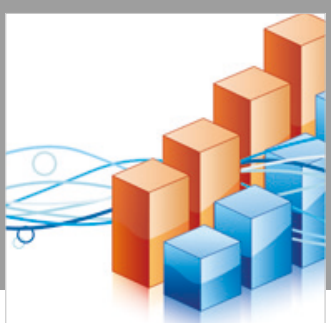

Advances in

Operations Research

\section{-n-m}
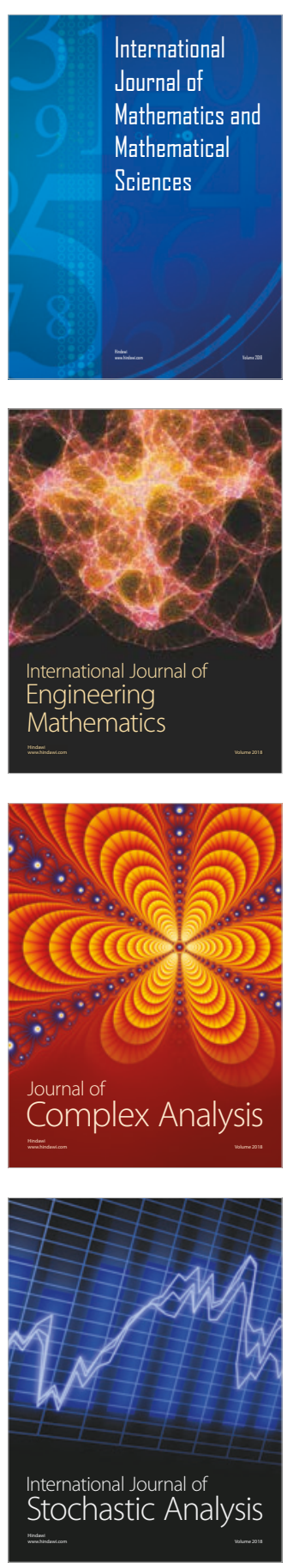
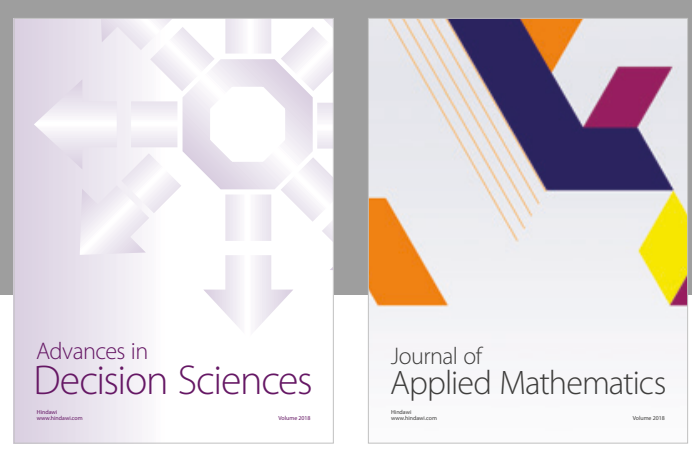

Journal of

Applied Mathematics
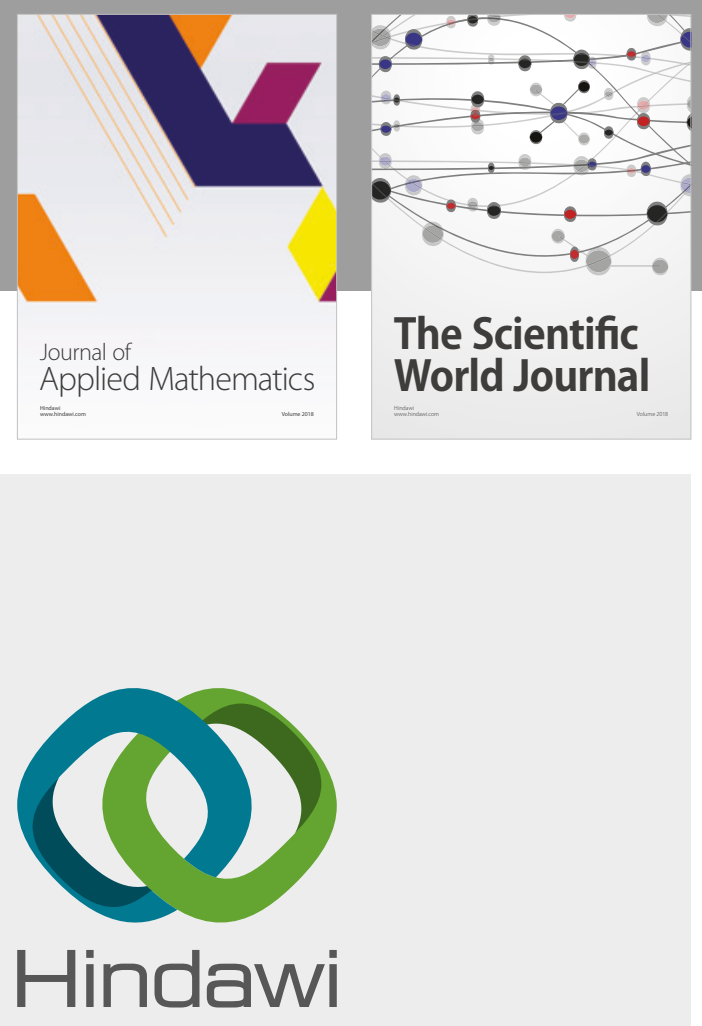

Submit your manuscripts at

www.hindawi.com

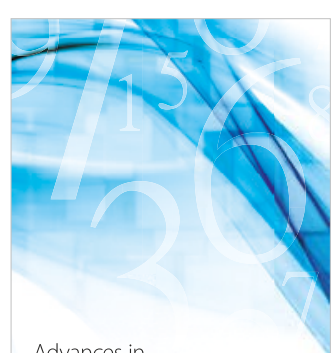

Advances in
Numerical Analysis
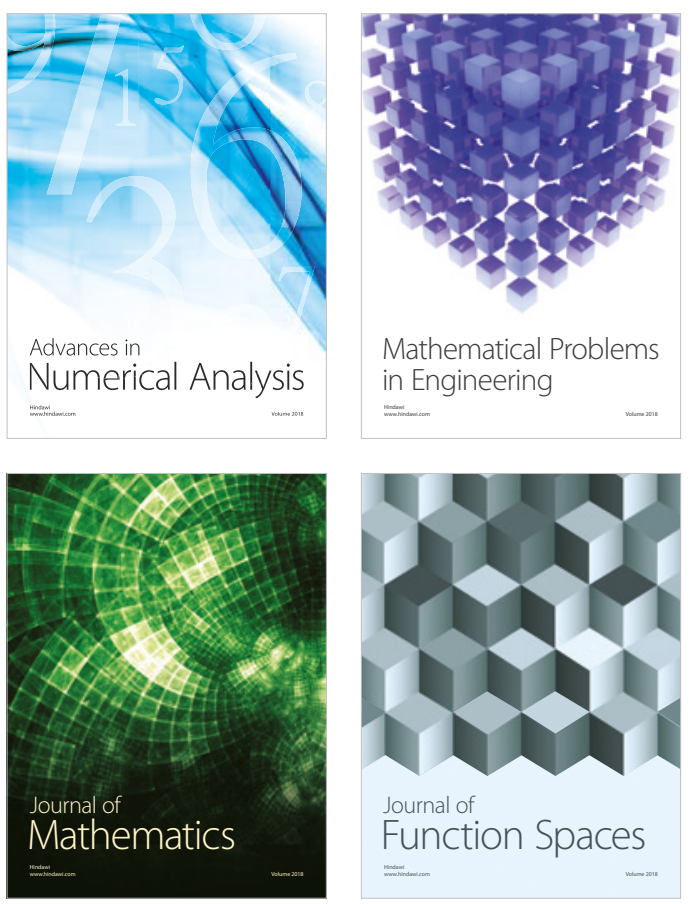

Mathematical Problems in Engineering

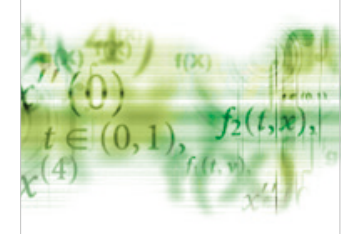

International Journal of

Differential Equations

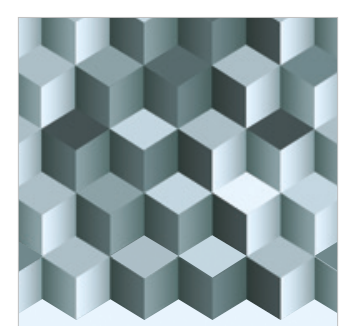

Journal of

Function Spaces
The Scientific

World Journal

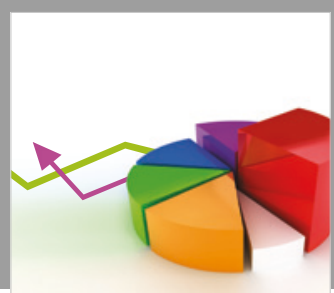

Journal of

Probability and Statistics
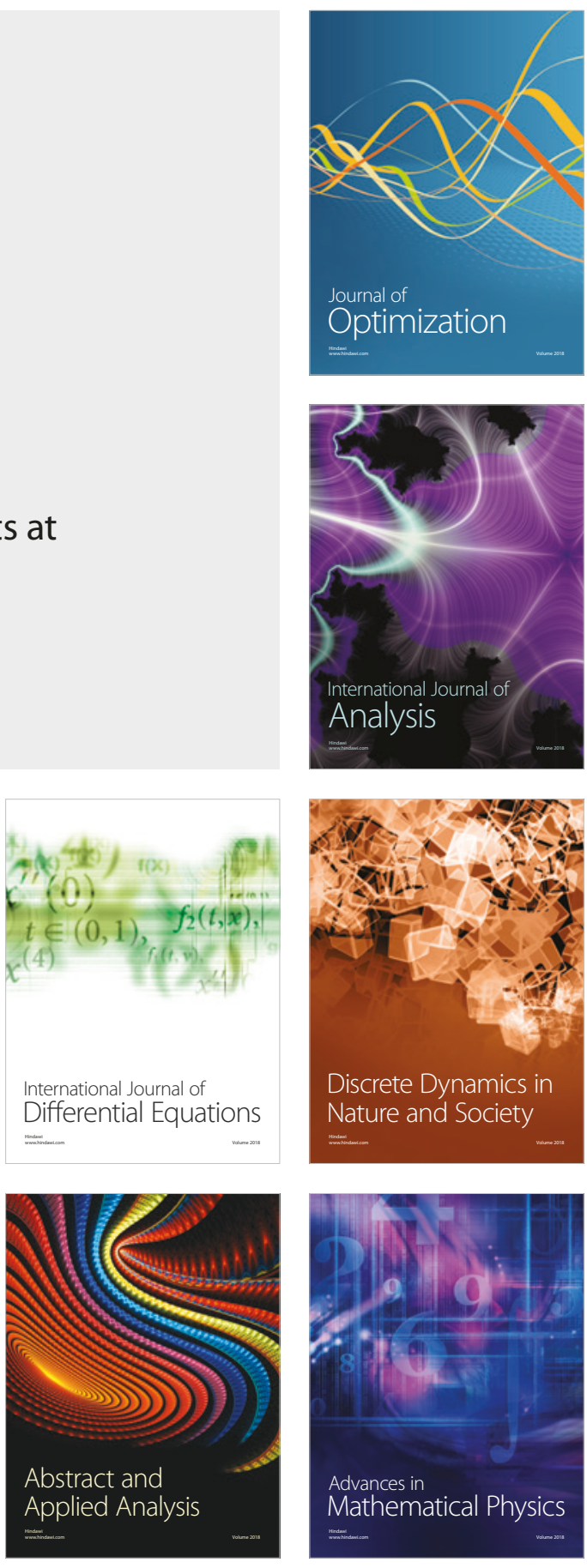